\title{
La Universidad y la nueva generación de estudiantes: Ios nativos digitales
}

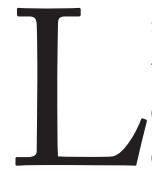

as universidades y los centros educativos en general están ante la presencia de una nueva generación de estudiantes. Estos estudiantes llamados por Marc Prensky como nativos digitales, tienen la característica común de haber nacido y crecido con la tecnología, incluyéndose dentro de esta generación, según los estudiosos del tema, a las personas con menos de 30 años.

$\mathrm{Y}$ en el caso de la Universidad $\mathrm{Na}-$ cional Autónoma de Honduras, (UNAH), un estudio realizado en el 2012 por el Doctor German Moncada, refleja que el 61\% de los aspirantes que hacen la Prueba de Aptitud Académica, (PAA), tienen edades entre los 16 y los 19 años, es decir la mayoría de los estudiantes de la UNAH son nativos digitales.

Según Prensky los nativos digitales son estudiantes con nuevas capacidades, con nuevas necesidades, con nuevas visiones de lo que son y quieren, tanto de sus docentes como de sus instituciones formadoras. Son estudiantes que quieren recibir información de forma ágil e inmediata, se sienten atraídos por multitareas y procesos paralelos, prefieren los gráficos a los textos, funcionan mejor y rinden más cuando trabajan en red, prefieren instruirse de forma lúdica a seguir en el rigor del trabajo tradicional.

Todas estas características, opuestas al modelo de enseñanza tradicional aún vigente en la mayoría de nues- tros centros educativos, desde el básico hasta el superior, coloca a las universidades ante un gran desafío, el de atender dos generaciones de estudiantes: la que arrastra las características del paradigma educativo del siglo XX y la generación de los nativos digitales.

La primera generación es formada con los métodos convencionales del texto impreso y del proceso paso a paso con una hegemonía de la charla magistral, paradigma bajo el cual nos formamos la mayoría de los que hoy trabajamos en las universidades desempeñando distintos roles. La segunda generación demanda un proceso de aprendizaje y de formación que se adapte a sus características y necesidades, lo que obliga a innovar en métodos y metodologías de enseñanza, de aprendizaje, de evaluación y en recursos educativos. Y no se trata de restarle valor al método de enseñanza tradicional, ello fue pertinente en su tiempo y en su momento, por ello la discusión y reflexión radica en que estamos frente a una sociedad donde los cambios vertiginosos en todas las áreas de vida del ser humano son la norma, donde el conocimiento se actualiza a ritmos antes inimaginables y donde la tecnología derivada del gran desarrollo científico, cada día nos sorprende más. Por eso, aun los que siendo de la generación pasada, la universidad está obligada a brindarles un proceso formativo acorde a los tiempos actuales.

Frente a este contexto de grandes retos, se vislumbra la oportunidad de un tiempo extraordinario para el aprendizaje y para la innovación educativa en las universidades y sistemas educativos en general.

Por ello quienes de una $\mathrm{u}$ otra forma son parte de la comunidad educativa -docentes, autoridades, gestores académicos e investigadores- poco a poco toman conciencia de que construir aprendizajes en el presente siglo, demanda nuevas estructuras organizativas marcadas por la flexibilidad, eliminar las restricciones educativas del siglo $\mathrm{XX}$, desaprender y aprender nuevos saberes o aprenderlos desde otras miradas pertinentes a las exigencias de la realidad actual, bajo metodologías de aprendizaje innovadoras y contenidos pertinentes y significativos.

No se debe olvidar que esta era digital y del conocimiento impone nuevas y mayores competencias profesionales, educativas y ciudadanas, que la universidad deberá fortalecer en sus estudiantes a fin de que egresen con las capacidades evidentes para aprender a conocer y aprender a aprender; y de esa forma asuman la formación permanente como parte de su actualización profesional. Y al mismo tiempo haga suyo el aprender haciendo y el aprender a convivir con los demás, para ser competitivos en un mundo laboral de altas exigencias profesionales y en una sociedad que demanda de sus ciudadanos, ser agentes de cambio, solidarios, pacíficos, éticos y responsables con su entorno. 